\title{
Formation of the $\left[\mathrm{Ge}_{4} \mathrm{O}_{16} \mathrm{Al}_{48}(\mathrm{OH})_{108}\left(\mathrm{H}_{2} \mathrm{O}\right)_{24}\right]^{20+}$ tetramer from con- densation of $\varepsilon-\mathrm{GeAl}_{12}$ Keggin polycations
}

\author{
Mohammad Shohel, Jennifer L. Bjorklund, Jack A. Smith, Sara E. Mason, Tori Z. Forbes* \\ Department of Chemistry, University of Iowa, Iowa City, IA-52242 \\ *Corresponding author: tori-forbes@uiowa.edu
}

\section{Supporting Information Placeholder}

\begin{abstract}
Keggin-type polyaluminum cations belong to a unique class of polyoxometalates (POMs) with their large positive charge, hydroxo bridges, and divergent isomerization/oligomerization. Previously reported oligomerizations of the polyaluminum cations were driven solely by the $\delta$-Keggin isomer, which created $\mathrm{Al}_{26}, \mathrm{Al}_{30}$, and $\mathrm{Al}_{32}$ dimeric species. We herein report the isolation of largest ever Keggin-type structure for this system through a unique mode of self-condensation among four $\varepsilon-\mathrm{GeAl}_{12}{ }^{8+}$ to form $\left[\mathrm{NaGe}_{4} \mathrm{O}_{16} \mathrm{Al}_{48}(\mathrm{OH})_{108}\left(\mathrm{H}_{2} \mathrm{O}\right)_{24}\right]^{21+}\left(\mathbf{G e}_{4} \mathbf{A l}_{48}\right)$. Elemental analysis confirms the $\mathrm{Ge}^{4+}$ substitution, and dynamic light scattering experiments indicated that these larger species exist in the thermally aged solutions. DFT calculations have revealed that a single atom $\mathrm{Ge}$ substitution in tetrahedral site of $\varepsilon-\mathrm{Al}_{13}{ }^{7+}$ is the key for the formation this cluster because it activates the deprotonation at certain octahedral sites to assist self-condensation in a specific mode.
\end{abstract}

Since the discovery of Keggin-type polyoxometalates (POMs) in $1933,{ }^{1}$ chemists and material scientists have been fascinated by their unique structural features and applications in energy, medicine, and water purification. The Keggin topology was first identified as a phosphotungstate and contains a central tetrahedrally coordinated cation encapsulated by 12 additional metal octahedra that are bridged through $\mathrm{OH}^{-}$or $\mathrm{O}^{2-}$ groups. The exterior metal cations can connect via shared edges or corners, which leads to five different isomeric $(\alpha, \beta, \gamma, \delta$, and $\varepsilon)$ forms. The chemical diversity for anionic POMs is vast, with the five Keggin isomers formed by octahedrally coordinated $\mathrm{V}, \mathrm{Mo}, \mathrm{W}, \mathrm{Nb}$, and Ta ions incapsulating $\mathrm{P}$, $\mathrm{Si}, \mathrm{Ge}$, or As cations. ${ }^{2}$ Structural topologies associated with cationic aluminum-based POMs are notably less diverse, with over $90 \%$ of the known species related to the $\delta$-, and $\varepsilon$-Keggin topology cations. Chemical diversity for the cationic aluminum POMs are also much more limited than what is observed for the anionic spe- cies, with only $\mathrm{Ga}^{3+}$ and $\mathrm{Ge}^{4+}$ full substitution reported for the tetrahedral position and $\mathrm{Ga}^{3+}$ and $\mathrm{Cr}^{3+}$ partial substitution reported in octahedral position. ${ }^{3-6}$ The chemical diversity of the Keggin-topology and the reactivity of these nanoscale clusters has resulted in their use within industrial catalysis and water purification. ${ }^{7-9}$ Additional efforts are ongoing to explore their use as metallodrugs for cancer treatement ${ }^{10}$, electrodes for $\mathrm{Li}^{+}$batteries and energy storage $^{11-12}$, multifunctional sensor ${ }^{13}$ and redox-based nonvolatile memory materials ${ }^{14}$. The metal oxo Keggin clusters containing aluminum, iron and others have also been found in natural systems and believe to control different geochemical processes. ${ }^{15-17}$

Keggin isomers can also undergo additional hydrolysis reactions or coordination with linkers that result in the formation of larger $(>1 \mathrm{~nm})$ oligomers. For the anionic POMs, formation of lacunary structures based upon the $\alpha$ - and $\beta$-Keggin motif results in the formation of these larger clusters, with the Wells-Dawson topology as a well-known example. Additional linkages occur through use of either organic linkers ${ }^{18}$ or octahedral/heteroatom substitution ${ }^{18}$ to create an array of larger anionic POMs based upon two to four Keggin clusters. For polyaluminum Keggin cations, the $\delta$-isomer is the only known synthon and either condenses to form the $\mathrm{Al}_{26}$ species or bridges through additional aluminum octahedra to create only two additional topologies $\left(\mathrm{Al}_{30}\right.$ or $\left.\mathrm{Al}_{32}\right) .{ }^{19-20} \mathrm{Cur}-$ rently, the largest known cationic POM topologies contains only contains two Keggin units and reflects a lack of understanding on the condensation process within the $\mathrm{Al}^{3+}$ system.

Previous studies have demonstrated that heteroatom substitution is important for the oligomerization process and can lead to a new understanding of the condensation process for cationic POMs. For example, Mothé-Esteves et al., indicated that octahedral substitution in Keggin units within anionic POMs can enhance formation of reversible $\mathrm{H}$-bond with other units, which further can condensate into bridging oxygen bond between two metals. ${ }^{21}$ This strategy has been employed to synthesize trimers ${ }^{22-23}$ and tetram$\mathrm{ers}^{24-30}$ of lacunary or tri-lacunary Keggin units within polyanionic 


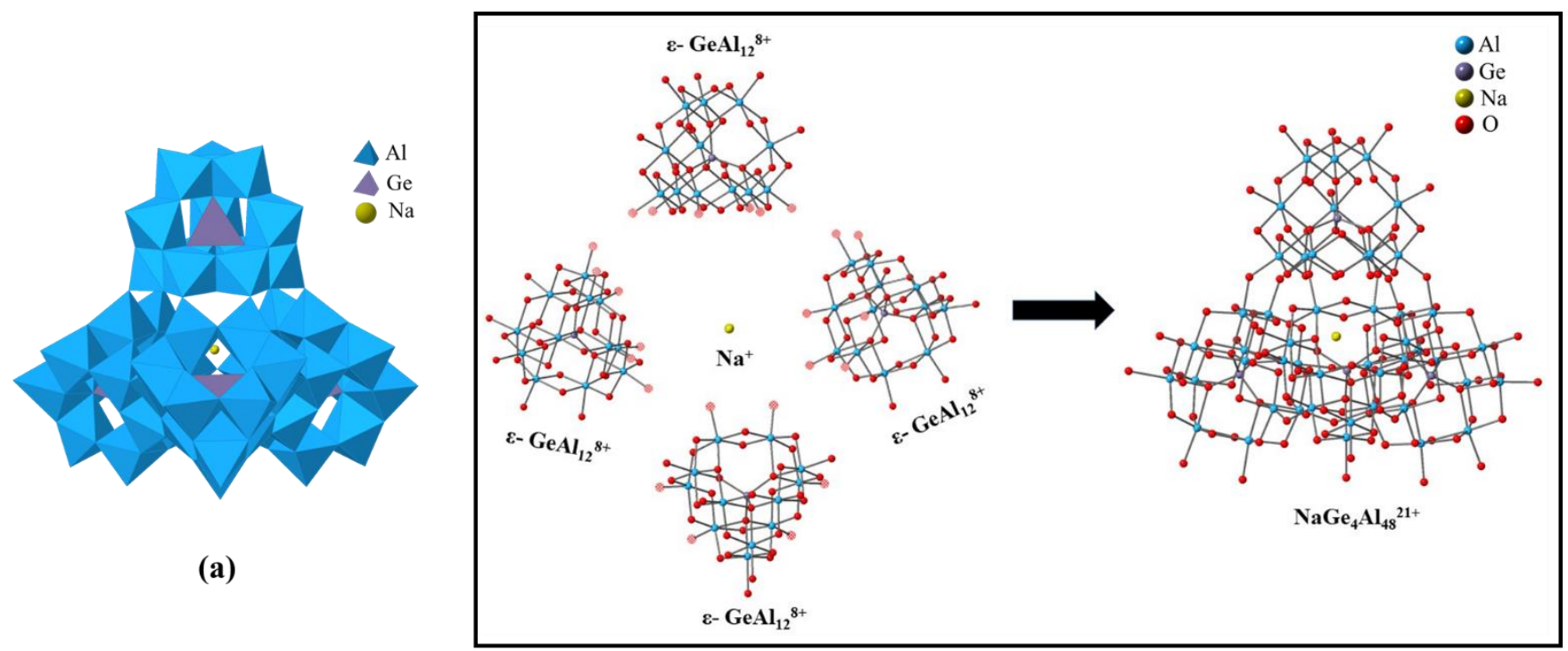

(b)

Figure 1. (a) Polyhedra representation of $\mathrm{NaGe}_{4} \mathrm{Al}_{48}{ }^{21+}$ Keggin cluster with $\mathrm{Al}^{3+}, \mathrm{Ge}^{4+}$ and $\mathrm{Na}^{+}$represented in blue, purple, and yellow, respectively. (b) Ball and stick representation for the formation of $\mathrm{NaGe}_{4} \mathbf{A l}_{\mathbf{4 8}}^{+\mathbf{2 1}}$ from individual $\varepsilon-\mathrm{GeAl}_{12}{ }^{8+}$ building block. The surface $\mathrm{H}_{2} \mathrm{O}$ groups that have undergone self-condensation are depicted by translucent red spheres.

POMs. In the case of cationic systems, previous computational work ${ }^{31}$ and experimental observations ${ }^{32-33}$ demonstrated that tetrahedral heteroatom substitution at center of $\mathrm{Al}_{13}{ }^{7+}$ Keggin can tune the chemical behavior of terminal $\mathrm{H}_{2} \mathrm{O}$ groups attached to octahedral metal ions. This surface reactivity is vital to the condensation process and may be utilized as synthetic strategy in $\mathrm{Al}^{3+}$ Keggin systems to generate larger POMs with novel chemical properties.

In the present study, we describe the synthesis and characterization of a giant $(\sim 2.4 \mathrm{~nm})$ Keggin-type aluminum oxo polycation $\left[\mathrm{NaGe}_{4} \mathrm{O}_{16} \mathrm{Al}_{48}(\mathrm{OH})_{108}\left(\mathrm{H}_{2} \mathrm{O}\right)_{24}\right]^{21+}\left(\mathbf{G e}_{4} \mathbf{A l}_{48}\right)$ composed of four $\varepsilon-$ $\mathrm{GeAl}_{12}$ Keggin units, without the use of lacunary structures or organic linkers. Additional investigations of the solution phase using Dynamic Light Scattering (DLS) provides evidence of the larger cluster within the solution phase. Density Functional Theory (DFT) calculations also provide an energetic understanding of the formation pathway and additional insights into the role of the counterions in the hydrolysis and condensation processes.

The $\mathrm{Ge}_{4} \mathrm{Al}_{48}$ cluster was synthesized by thermal aging of an aqueous solution containing $\mathrm{Al}^{3+}$ and $\mathrm{Ge}^{4+}$ cation. Initially, a mixed $\mathrm{Al}^{3+} / \mathrm{Ge}^{4+}$ solution was partially hydrolyzed at $80{ }^{\circ} \mathrm{C}$, which is the standard procedure for forming the $\left.\left[\mathrm{GeO}_{4} \mathrm{Al}_{12} \mathrm{OH}_{24} \mathrm{H}_{2} \mathrm{O}_{12}\right)\right]^{8+}\left(\varepsilon-\mathrm{GeAl}_{12}\right)$ Keggin. ${ }^{4}$ Evaporation of the solution at this point with addition of selenate anions results in the crystallization of the $\left[\mathrm{GeO}_{4} \mathrm{Al}_{12}(\mathrm{OH})_{24}\left(\mathrm{H}_{2} \mathrm{O}\right)_{12}\right]\left(\mathrm{SeO}_{4}\right)_{4} \cdot 14 \mathrm{H}_{2} \mathrm{O}$ phase. Additional thermal aging of this solution at $90{ }^{\circ} \mathrm{C}$ for seven days, followed by addition of the 2,6- napthalenedisulfonate (2,6NDS) ion yielded small, transparent crystals of $\left[\mathrm{NaGe}_{4} \mathrm{O}_{16} \mathrm{Al}_{48}(\mathrm{OH})_{108}\left(\mathrm{H}_{2} \mathrm{O}\right)_{24}\right](2,6-\mathrm{NDS})_{7} \mathrm{Cl}_{7}\left(\mathrm{H}_{2} \mathrm{O}\right)_{45}$ with approximate yields of $15 \%$ based on $\mathrm{Al}^{3+}$.

Structural features of the solid-state material was analyzed using single crystal X-ray diffraction and indicated that the $\mathrm{Ge}_{4} \mathrm{Al}_{48}$ cluster is based upon the $\varepsilon$-Keggin unit. Each $\varepsilon$-isomer is composed of a tetrahedral $\mathrm{Ge}(\mathrm{O})_{4}$ unit surrounded by $12 \mathrm{Al}(\mathrm{OH})_{6}$ octahedra that are connected via edge-sharing $\mu_{2}-\mathrm{OH}$ groups between
$\mathrm{Al}_{3}(\mathrm{OH})_{6}\left(\mathrm{H}_{2} \mathrm{O}\right)_{3}$ trimers (Fig. 1). The $\mathrm{Ge}-\mathrm{O}$ bond distances ranged from $1.760(11)$ to $1.806(10) \AA$ and are similar to the isolated $\varepsilon$ $\mathrm{GeAl}_{12}{ }^{8+}$ Keggin $(\mathrm{Ge}-\mathrm{O}=1.809(8) \AA)^{4}{ }^{4} \mathbf{G e}_{4} \mathbf{A l}_{48}$ is formed when four $\varepsilon-\mathrm{GeAl}_{12}$ units are linked via twelve $\mu_{2}-\mathrm{OH}$ bridging groups (two linkages per trimeric unit) in a tetrahedral $\left(T_{d}\right)$ arrangement. A $0.9 \mathrm{~nm}$ cavity exists at the center of the $\mathbf{G e}_{4} \mathbf{A l}_{48}$ cluster, but Xray diffraction could only identify a single $\mathrm{Na}^{+}$cation within this space. The $\left[\mathrm{Na}\left(\mathrm{Ge}_{4} \mathrm{Al}_{48}\right)\right]^{21+}$ unit is charge balanced by seven 2,6napthalenedisulfonate and seven chloride ions for an overall compound formula of $\left[\mathrm{NaGe}_{4} \mathrm{O}_{16} \mathrm{Al}_{48}(\mathrm{OH})_{108}\left(\mathrm{H}_{2} \mathrm{O}\right)_{24}\right](2,6-$ $\mathrm{NDS})_{7} \mathrm{Cl}_{7}\left(\mathrm{H}_{2} \mathrm{O}\right)_{45}$. The 2,6-napthalenedisulfonate ions are arranged within two separate channels in the [010] and [101] directions. These anions aid in the crystallization of the $\mathrm{Ge}_{4} \mathrm{Al}_{48}$ cluster by engaging in both $\pi-\pi$ interaction between the naphthalene rings and electrostatics with the positively charged clusters. ${ }^{19}$

The structural topology observed in $\mathbf{G} \mathbf{e}_{\mathbf{4}} \mathbf{A l}_{\mathbf{4 8}}$ is unique because it is the only giant cationic tetrahedron formed through non-lacunary $\varepsilon$-isomers within the POM family of compounds. A handful of large tetrahedron forms have been reported for polyanions, but they only occurs through Dawson lacunary clusters ${ }^{29-30,34}$ or other lacunary fragments. ${ }^{27-28,}$, 35-36 Only one compound reported by Hussain et al. contains direct linkages between the $\beta$-Keggin isomer $\left[\left(\beta-\mathrm{Ti}_{2} \mathrm{SiW}_{10} \mathrm{O}_{39}\right)_{4}\right]^{24-}$ but forms a circular wheel instead of a larger tetrahedral unit. ${ }^{37}$ The wheel also contains three $\mathrm{K}^{+}$ions, one present in the central cavity and another two act as "wheel caps". The presence of the $\mathrm{Ti}^{4+}$ cations as a surface reactive species was found to be key to the formation of this larger Keggin-based cluster as it provides an avenue for additional hydrolysis and condensation.

Additional chemical characterization of this system confirms the heteroatom content and the presence of the oligomerized $\mathbf{G e}_{4} \mathbf{A l}_{\mathbf{4 8}}$ cluster in thermally aged solutions. Solid-state crystals were dissolved in an acidic solution and the elemental content was analyzed by ICP-MS. The theoretical Al:Ge ratio for the $\mathrm{Ge}_{4} \mathrm{Al}_{48}{ }^{20+}$ cluster is 12 and our experimental value was $12.43 \pm 0.45$ (Table S1), which is within error of the expected value. Formation 
of the $\mathrm{Ge}_{4} \mathrm{Al}_{48}{ }^{20+}$ tetramer in solution was also supported by the hydrodynamic diameter measurement of Keggin ions by Dynamic Light Scattering (DLS) measurements (Fig. 2). The unaged, partially hydrolyzed $\mathrm{Ge}^{4+} / \mathrm{Al}^{3+}$ stock solution displays one peak in the

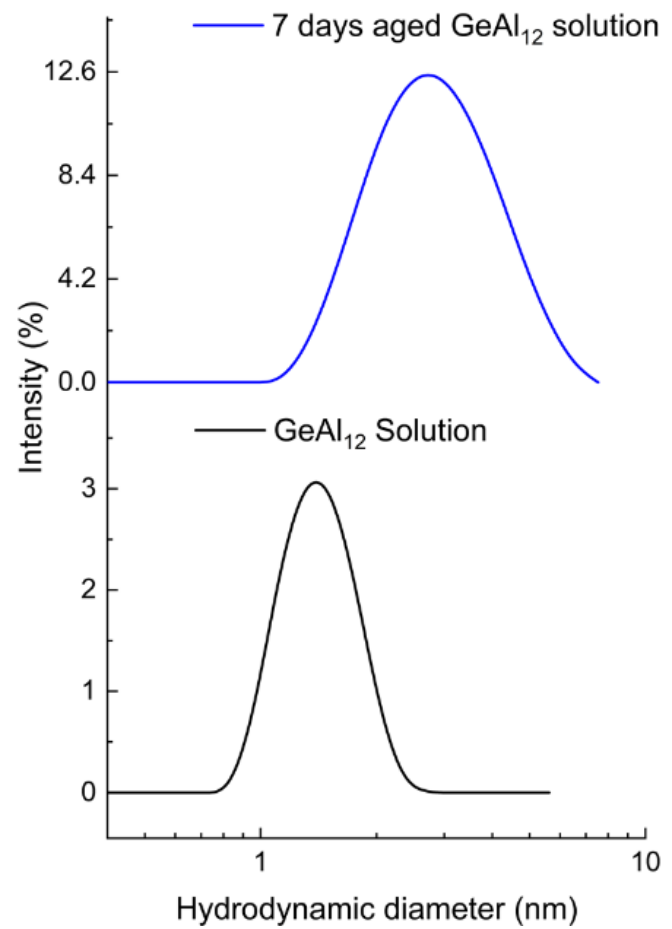

Figure 2. Particle size distribution from DLS of as prepared $\mathrm{GeAl}_{12}$ solution and after aging 7 days at $90{ }^{\circ} \mathrm{C}$.

DLS plot with a peak centroid at $1.2 \mathrm{~nm}$. This value is consistent with the theoretical value for the size of $\varepsilon-\mathrm{GeAl}_{12}$ cluster. Upon thermal aging, the single peak in the DLS plot broadens and shifts to a higher particle size. The peak centroid in the aged solutions is at 2.8 nanometers, which is now consistent with the formation of the $\mathrm{Ge}_{4} \mathrm{Al}_{48}{ }^{20+}$ tetramer.

One important aspect of the formation of the $\mathrm{Ge}_{4} \mathrm{Al}_{48}{ }^{20+}$ tetramer is the divergence from the previously studied $\mathrm{Al}^{3+}$ and $\mathrm{Al}^{3+} / \mathrm{Ga}^{3+}$ systems. ${ }^{5,19}$ Oligomerization within these systems initially begins with the conversion of the $\varepsilon$-Keggin form to the $\delta$ isomer. Previous studies have postulated that rotated trimer of the $\delta-\mathrm{Al}_{13}$ and $\delta-\mathrm{GaAl}_{12}$ is a reactive site, which can form larger clusters by self-condensation $\mu_{2}-\mathrm{OH}$ bridging or use of additional $\mathrm{Al}^{3+}$ octahedra to link fragments together. ${ }^{5,}{ }^{19}$ In the $\mathrm{Al}^{3+} / \mathrm{Ge}^{4+}$ system there is no experimental evidence for the formation of the $\delta$-isomer and the $\mathrm{Ge}_{4} \mathrm{Al}_{48}{ }^{20+}$ tetramer offers the glimpse into the structural features of the condensation product within this system. Our initial hypotheses regarding the formation of the $\mathrm{Ge}_{4} \mathrm{Al}_{48}{ }^{20+}$ tetramer is that the $\varepsilon-\mathrm{GeAl}_{12}$ synthon has reactive terminal $\mathrm{H}_{2} \mathrm{O}$ groups that allow for condensation into $\mathrm{Ge}_{4} \mathrm{Al}_{48}{ }^{20+}$. We use Density Functional Theory (DFT) calculations to test this hypothesis and provide additional insights into the system.

The surface reactivity of the $\varepsilon$ - and $\delta$-isomers for $\mathrm{Al}_{13}$ and $\mathrm{GeAl}_{12}$ clusters was investigated to further evaluate the condensation process. We have previously used modeled outer-sphere adsorption of sulfate as a probe of cluster surface reactivity. In some cases, the adsorption leads to the deprotonation of different surface sites over the course of geometry optimization, thus identifying relatively labile protons While sulfate anions are not present in the thermally aged solution, they are effective as a probe adsorbate to identify the most acidic proton that can act as the driving force for the formation of this tetramer. This modeling approach has been applied to the $\delta-\mathrm{GaAl}_{12}$ cluster, where it was used to establish that the driving force for oligomerization is deprotonation of the rotated trimer. ${ }^{5}$ Here, we again use modeled adsorption with a sulfate probe to study how $\mathrm{Ge}^{4+}$ substitution effects on surface reactivity (in terms of adsorption energies and ease of deprotonation) of the $\varepsilon$ and $\delta$-isomers for the $\mathrm{Al}_{13}$ and $\mathrm{GeAl}_{12}$ and the formation of $\mathrm{Ge}_{4} \mathrm{Al}_{48}{ }^{20+}$ (additional details in SI).

We model sulfate-cluster interactions starting from two chemically-distinct starting configurations (referred to as Sites 1 and 2) for $\varepsilon-\mathrm{Al}_{13}$ and $\varepsilon-\mathrm{GeAl}_{12}$ Keggin clusters (Fig. 3b). In Site 1, the anion is positioned to interact with two terminal $\eta_{1}-\mathrm{H}_{2} \mathrm{O}$ groups on two different $\mathrm{Al}_{3}(\mathrm{OH})_{6}\left(\mathrm{H}_{2} \mathrm{O}\right)_{3}$ trimers, corresponding to point where the $\varepsilon-\mathrm{GeAl}_{12}$ Keggin clusters oligomerize into the $\mathrm{Ge}_{4} \mathrm{Al}_{48}{ }^{20+}$ tetramer. In Site 2, the sulfate anion can engage with a mixture of $\eta_{1}-\mathrm{H}_{2} \mathrm{O}$ and $\mu_{2}-\mathrm{OH}$ groups on the surface of one $\mathrm{Al}_{3}(\mathrm{OH})_{6}\left(\mathrm{H}_{2} \mathrm{O}\right)_{3}$ trimer unit. We compare changes in the Mulliken population $\left(\Delta q_{\mathrm{m}}\right)$ to deprotonation events. Of the four $\varepsilon$-Keggin interactions, only Site 1 sulfate interactions with $\varepsilon-\mathrm{GeAl}_{12}$ (Table $\mathrm{S} 2$ and Figure 2) result in deprotonation and a $\Delta q_{\mathrm{m}}$ value greater than 0.50 e. All other interactions have $\Delta q_{\mathrm{m}}$ values of less than 0.50 e and did not exhibit deprotonation, similar to previous observations on Kegginanion interactions. $5,31,38$

To bridge the understanding between isomers and heteroatom identity with regard to condensation reactions, we also assessed the $\delta$-isomers for $\mathrm{GeAl}_{12}$ and $\mathrm{Al}_{13}$ using the sulfate anion as our probe adsorbate (Table S3 and Figure S1). The $\varepsilon$-isomer has four equivalent edge-sharing trimers whereas the $\delta$-isomer has three edge-sharing trimers and one rotated, corner-sharing trimer. The number of corner- versus edge-trimers influences the surface reactivity of the nanocluster. For the $\delta$-isomer, three chemically distinct sites can be found on Keggin surface that correspond to interactions with $\eta_{1-}$ $\mathrm{H}_{2} \mathrm{O}$ and $\mu_{2}-\mathrm{OH}$ groups on the different $\mathrm{Al}_{3}(\mathrm{OH})_{6}\left(\mathrm{H}_{2} \mathrm{O}\right)_{3}$ units. For $\delta$ - $\mathrm{Al}_{13}$, deprotonation only occurs associated with the reactive trimer (rotated $\mathrm{Al}_{3}(\mathrm{OH})_{6}\left(\mathrm{H}_{2} \mathrm{O}\right)_{3}$ group), whereas higher charge transfer and deprotonation is observed for all sites on the $\delta$-GeAl ${ }_{12}$ clusters (Table S3). Our calculation confirms that deprotonation events for the reactive site on the $\delta-\mathrm{Al}_{13}$ leads to the formation of $\mathrm{Al}_{26}, \mathrm{Al}_{30}$ or $\mathrm{Al}_{32}$. However, the high charge transfer on all surface sites associate the $\delta-\mathrm{GeAl}_{12}$ cluster suggests that random condensation will occur and likely form amorphous precipitates.

In summary, we have reported the synthesis and characterization of a new cationic POM tetramer $\left(\mathrm{Ge}_{4} \mathrm{Al}_{48}{ }^{20+}\right)$ composed solely of $\varepsilon$-Keggin units without any lacunary features or organic linkers. DLS experiments indicate that this large tetramer occurs in partially hydrolyzed solutions containing $\mathrm{Al}^{3+}$ and $\mathrm{Ge}^{4+}$ after thermal aging for seven days. DFT calculations indicated that $\mathrm{Ge}^{4+}$ substitution at the central tetrahedral site of the Keggin topology is key to the formation of the tetramer because it specifically deprotonates $\eta_{1}-\mathrm{H}_{2} \mathrm{O}$ to form symmetric $\mu_{2}-\mathrm{OH}$ bridges, which can be linked to the formation of the tetramer. This work has demonstrated the importance of the metal cation identity to control stability and reactivity, even when it is located at the center of the Keggin cluster. More broadly, it provides additional details in the nucleation process of metal oxide and hydroxide phases from POM synthons that can be used to provide additional controls on the development of functional materials. 

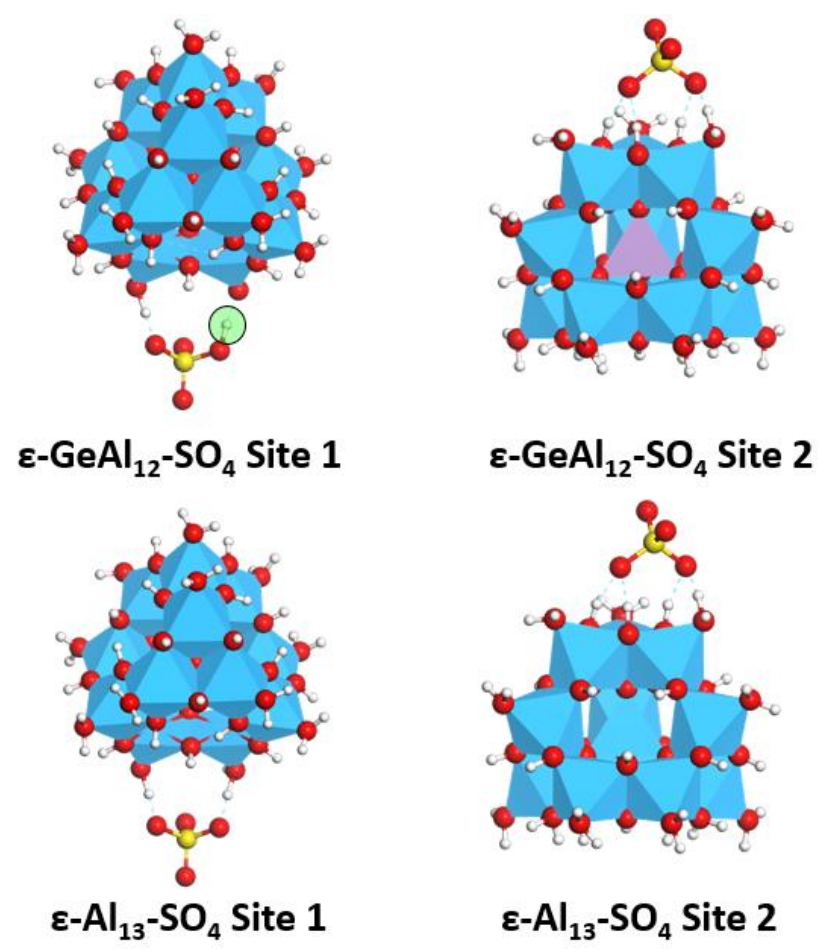

Figure 3. Different surface sites of $\varepsilon-\mathrm{GeAl}_{12}$ and $\varepsilon-\mathrm{Al}_{13}$ interacting with $\mathrm{SO}_{4}{ }^{2-}$ ion. The abstracted proton is highlighted with a green circle. Blue and purple polyhedra are used to represent $\mathrm{Al}$ and Ge atoms, respectively. Red, yellow and white balls are used to represent $\mathrm{O}, \mathrm{S}$, and $\mathrm{H}$ atoms, respectively.

\section{ASSOCIATED CONTENT}

\section{Supporting Information}

A supporting information file in pdf format is available free of charge on the ACS Publications website (http://pubs.acs.org). The supporting information file contains experimental details, result of elemental analysis, result of computational calculation and additional figures. Additional crystallographic information files can be found on the Cambridge Structural Database by requesting deposition numbers 2027043.

\section{AUTHOR INFORMATION}

\section{Corresponding Author}

*Tori Z. Forbes: tori-forbes@uiowa.edu

\section{Author Contributions}

TZF and SEM provided resources, support and funding to carryout the study. MS and JAS did the synthesis experiment. MS did all the chemical characterization, crystallography and experimental data analysis. JLB conducted all of the DFT calculations. MS and JLB prepared the initial draft of manuscript. All authors contributed to the writing and editing of final manuscript for the submission.

\section{Notes}

The authors declare no competing financial interests.

\section{ACKNOWLEDGMENT}

SEM acknowledges computational resources provided by the University of Iowa. This work used the Extreme Science and Engineering Discovery Environment (XSEDE),${ }^{39}$ which is supported by the National Science Foundation grant number ACI-1548562 though allocation TG-GEO160006. We acknowledge Prof. Aliasger Salem and Dr. Lr Jaidev Chakka (UI college of Pharmacy) for their help regarding DLS experiment. TZF and MS also acknowledge American Crystallographic Association (ACA) summer school 2019 at Northwestern University for their travel support to teach MS advanced-level crystallography. JLB acknowledges support from the University of Iowa's Dissertation Writing Fellowship.

\section{REFERENCES}

1. Keggin, J. F., Structure of the Molecule of 12-Phosphotungstic Acid. Nature 1933, 131 (3321), 908-909.

2. Li, D.; Ma, P.; Niu, J.; Wang, J., Recent advances in transitionmetal-containing Keggin-type polyoxometalate-based coordination polymers. Coordination Chemistry Reviews 2019, 392, 49-80.

3. Parker, W. O. N.; Millini, R.; Kiricsi, I., Metal Substitution in Keggin-Type Tridecameric Aluminum-Oxo-Hydroxy Clusters. Inorganic Chemistry 1997, 36 (4), 571-575.

4. Lee, A. P.; Phillips, B. L.; Olmstead, M. M.; Casey, W. H., Synthesis and Characterization of the GeO4Al12(OH)24(OH2)128+ Polyoxocation. Inorganic Chemistry 2001, 40 (17), 4485-4487.

5. Shohel, M.; Bjorklund, J. L.; Ovrom, E. A.; Mason, S. E.; Forbes, T. Z., Ga3+ Incorporation into A113 Keggin Polyoxometalates and the Formation of $\delta$-(GaAl12)7+ and (Ga2.5A128.5)19+ Polycations. Inorganic Chemistry 2020, 59 (15), 10461-10472.

6. Wang, W.; Fullmer, L. B.; Bandeira, N. A. G.; Goberna-Ferrón, S.; Zakharov, L. N.; Bo, C.; Keszler, D. A.; Nyman, M., Crystallizing Elusive Chromium Polycations. Chem 2016, 1 (6), 887-901. 
Muñoz, M.; Romanelli, G.; Botto, I. L.; Cabello, C. I.; Lamonier, C.; Capron, M.; Baranek, P.; Blanchard, P.; Payen, E., Al13-[X$\mathrm{Mo} / \mathrm{WOn}](\mathrm{X}=\mathrm{Al}, \mathrm{Co}, \mathrm{V}, \mathrm{P})$ composites as catalysts in clean oxidation of aromatic sulfides. Applied Catalysis B: Environmental 2010, 100 (1), 254263.

8. Benito, I.; del Riego, A.; Martínez, M.; Blanco, C.; Pesquera, C.; González, F., Toluene methylation on A113- and GaAl12-pillared clay catalysts. Applied Catalysis A: General 1999, 180 (1), 175-182.

9. Stewart, T. A.; Trudell, D. E.; Alam, T. M.; Ohlin, C. A.; Lawler, C.; Casey, W. H.; Jett, S.; Nyman, M., Enhanced Water Purification: A Single Atom Makes a Difference. Environmental Science \& Technology 2009, 43 (14), 5416-5422.

10. Bijelic, A.; Aureliano, M.; Rompel, A., Polyoxometalates as Potential Next-Generation Metallodrugs in the Combat Against Cancer. Angewandte Chemie International Edition 2019, 58 (10), 2980-2999.

11. Yeo, H. J.; Paik, Y.; Paek, S.-M.; Honma, I., Keggin-type aluminum polyoxocation/graphene oxide hybrid as a new nanostructured electrode for a lithium ion battery. Journal of Physics and Chemistry of Solids 2012, 73 (12), 1417-1419.

12. Priyadarshini, M.; Shanmugan, S.; Kirubakaran, K. P.; Thomas, A.; Prakash, M.; Senthil, C.; Lee, C. W.; Vediappan, K., High energy storage of Li-ions on keggin-type polyoxometalate as electrodes for rechargeable lithium batteries. Journal of Physics and Chemistry of Solids 2020, 142, 109468.

13. Wang, G.; Zhou, J.; Li, J., Layer-by-layer self-assembly aluminum Keggin ions/Prussian blue nanoparticles ultrathin films towards multifunctional sensing applications. Biosensors and Bioelectronics 2007, 22 (12), 2921-2925.

14. Chen, X.; Huang, P.; Zhu, X.; Zhuang, S.; Zhu, H.; Fu, J.; Nissimagoudar, A. S.; Li, W.; Zhang, X.; Zhou, L.; Wang, Y.; Lv, Z.; Zhou, Y.; Han, S.-T., Keggin-type polyoxometalate cluster as an active component for redox-based nonvolatile memory. Nanoscale Horizons 2019, 4 (3), 697-704.

15. $\quad$ Furrer, G.; Phillips, B. L.; Ulrich, K.-U.; Pöthig, R.; Casey, W. H., The Origin of Aluminum Flocs in Polluted Streams. Science 2002, 297 (5590), 2245.

16. Sadeghi, O.; Zakharov, L. N.; Nyman, M., Aqueous formation and manipulation of the iron-oxo Keggin ion. Science 2015, 347 (6228), 1359.

17. Nyman, M., Polyoxometalates and Other Metal-Oxo Clusters in Nature. In Encyclopedia of Geochemistry: A Comprehensive Reference Source on the Chemistry of the Earth, White, W. M., Ed. Springer International Publishing: Cham, 2016; pp 1-5.

18. Long, D.-L.; Burkholder, E.; Cronin, L., Polyoxometalate clusters, nanostructures and materials: From self assembly to designer materials and devices. Chemical Society Reviews 2007, 36 (1), 105-121.

19. Abeysinghe, S.; Unruh, D. K.; Forbes, T. Z., Crystallization of Keggin-Type Polyaluminum Species by Supramolecular Interactions with Disulfonate Anions. Crystal Growth \& Design 2012, 12 (4), 2044-2051.

20. Sun, Z.; Wang, H.; Tong, H.; Sun, S., A Giant Polyaluminum Species S-A132 and Two Aluminum Polyoxocations Involving Coordination by Sulfate Ions $\mathrm{S}-\mathrm{Al} 32$ and $\mathrm{S}-\mathrm{K}-\mathrm{Al13}$. Inorganic Chemistry 2011, 50 (2), 559-564.

21. Mothé-Esteves, P.; Pereira, M. M.; Arichi, J.; Louis, B., How Keggin-Type Polyoxometalates Self-Organize into Crystals. Crystal Growth \& Design 2010, 10 (1), 371-378.

22. Matsunaga, S.; Inoue, Y.; Mihara, K.; Nomiya, K., Synthesis and crystal structure of hexacerium(IV) cluster-containing Keggin polyoxometalate trimer. Inorganic Chemistry Communications 2017, 80, 61-64.

23. Al-Kadamany, G. A.; Hussain, F.; Mal, S. S.; Dickman, M. H.; Leclerc-Laronze, N.; Marrot, J.; Cadot, E.; Kortz, U., Cyclic Ti9 Keggin Trimers with Tetrahedral (PO4) or Octahedral (TiO6) Capping Groups. Inorganic Chemistry 2008, 47 (19), 8574-8576.

24. Sakai, Y.; Yoza, K.; Kato, C. N.; Nomiya, K., Tetrameric, Trititanium(IV)-Substituted Polyoxotungstates with an $\alpha$-Dawson Substructure as Soluble Metal-Oxide Analogues: Molecular Structure of the Giant "Tetrapod" $[(\alpha-1,2,3-\mathrm{P} 2 \mathrm{~W} 15 \mathrm{Ti} 3 \mathrm{O} 62) 4\{\mu 3-\mathrm{Ti}(\mathrm{OH}) 3\} 4 \mathrm{Cl}] 45-$. Chemistry - A European Journal 2003, 9 (17), 4077-4083.
25. Sakai, Y.; Ohta, S.; Shintoyo, Y.; Yoshida, S.; Taguchi, Y.; Matsuki, Y.; Matsunaga, S.; Nomiya, K., Encapsulation of Anion/Cation in the Central Cavity of Tetrameric Polyoxometalate, Composed of Four Trititanium(IV)-Substituted $\alpha$-Dawson Subunits, Initiated by Protonation/Deprotonation of the Bridging Oxygen Atoms on the Intramolecular Surface. Inorganic Chemistry 2011, 50 (14), 6575-6583.

26. Zhang, Z.; Wang, Y.-L.; Yang, G.-Y., An unprecedented Zrcontaining polyoxometalate tetramer with mixed trilacunary/dilacunary Keggin-type polyoxotungstate units. Acta Crystallographica Section C Structural Chemistry 2018, 74 (11), 1284-1288.

27. Zhao, J.-W.; Zhang, J.; Zheng, S.-T.; Yang, G.-Y., Combination of Lacunary Polyoxometalates and High-Nuclear Transition-Metal Clusters under Hydrothermal Conditions. 5. A Novel Tetrameric Cluster of $[\{\mathrm{FeIIFeIII12}(\mu 3-\mathrm{OH}) 12(\mu 4-\mathrm{PO} 4) 4\}(\mathrm{B}-\alpha-\mathrm{PW} 9 \mathrm{O} 34) 4] 22 . \quad$ Inorganic Chemistry 2007, 46 (26), 10944-10946.

28. Wang, K.-Y.; Bassil, B. S.; Lin, Z.-G.; Haider, A.; Cao, J.; Stephan, H.; Viehweger, K.; Kortz, U., Ti7-containing, tetrahedral 36tungsto-4-arsenate(iii) [Ti6(TiO6)(AsW9O33)4]20-. Dalton Transactions 2014, 43 (43), 16143-16146.

$29 . \quad$ Pradeep, C. P.; Long, D.-L.; Kögerler, P.; Cronin, L., Controlled assembly and solution observation of a $2.6 \mathrm{~nm}$ polyoxometalate 'super' tetrahedron cluster: [KFe12(OH)18( $\alpha-1,2,3-\mathrm{P} 2 \mathrm{~W} 15 \mathrm{O} 56) 4] 29-$. Chemical Communications 2007, (41), 4254-4256.

30. Yoshitaka, S.; Shoko, Y.; Takeshi, H.; Hideyuki, M.; Kenji, N., Tetrameric, Tri-Titanium(IV)-Substituted Polyoxometalates with an $\alpha$ Dawson Substructure as Soluble Metal Oxide Analogues. Synthesis and Molecular Structure of Three Giant "Tetrapods" Encapsulating Different Anions (Br-, I-, and NO3-). Bulletin of the Chemical Society of Japan 2007, 80 (10), 1965-1974.

31. Bjorklund, J. L.; Bennett, J. W.; Forbes, T. Z.; Mason, S. E., Modeling of MA112 Keggin Heteroatom Reactivity by Anion Adsorption. Crystal Growth \& Design 2019, 19 (5), 2820-2829.

32. Lee, A. P.; Furrer, G.; Casey, W. H., On the Acid-Base Chemistry of the Keggin Polymers: GaA112 and GeA112. Journal of Colloid and Interface Science 2002, 250 (1), 269-270.

33. Lee, A. P.; Phillips, B. L.; Casey, W. H., The kinetics of oxygen exchange between the GeO4Al12(OH)24(OH2)128+(aq) molecule and aqueous solutions. Geochimica et Cosmochimica Acta 2002, 66 (4), 577 587.

34. Sakai, Y.; Yoza, K.; Kato, C. N.; Nomiya, K., A first example of polyoxotungstate-based giant molecule. Synthesis and molecular structure of a tetrapod-shaped Ti-O-Ti bridged anhydride form of Dawson tri-titanium(iv)-substituted polyoxotungstate. Dalton Transactions 2003, (18), 3581-3586.

35. Al-Kadamany, G. Synthesis, Structure and Catalytic Activity of Titanium, Zirconium and Hafnium-Containing Polyoxometalates. Jacobs University, IRC-Library, Information Resource Center der Jacobs University Bremen, 2010 .

36. Kim, G.-S.; Zeng, H.; VanDerveer, D.; Hill, C. L., A Supramolecular Tetra-Keggin Polyoxometalate [Nb4O6( $\alpha$ Nb3SiW9O40)4]20-Angewandte Chemie International Edition 1999, 38 (21), 3205-3207.

37. Hussain, F.; Bassil, B. S.; Bi, L.-H.; Reicke, M.; Kortz, U., Structural Control on the Nanomolecular Scale: Self-Assembly of the Polyoxotungstate Wheel [ $\{\beta-\mathrm{Ti} 2 \mathrm{SiW} 10 \mathrm{O} 39\} 4] 24-$. Angewandte Chemie International Edition 2004, 43 (26), 3485-3488.

38. Bennett, J. W.; Bjorklund, J. L.; Forbes, T. Z.; Mason, S. E., Systematic Study of Aluminum Nanoclusters and Anion Adsorbates. Inorganic Chemistry 2017, 56 (21), 13014-13028.

39. John Towns, T. C., Maytal Dahan, Ian Foster, Kelly Gaither, Andrew Grimshaw, Victor Hazlewood, Scott Lathrop, Dave Lifka, Gregory D. Peterson, Ralph Roskies, J. Ray Scott, Nancy Wilkins-Diehr, XSEDE: Accelerating Scientific Discovery. Computing in Science \& Engineering 2014, 16 (5), 62-74. 


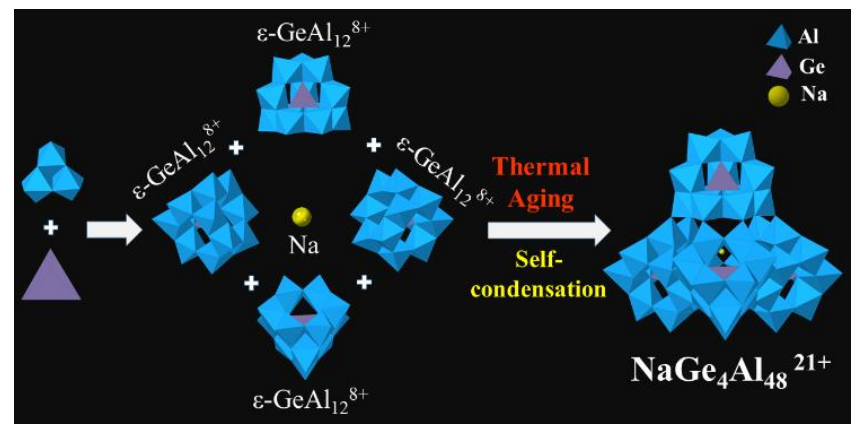

The proposed mechanism for the formation of tetrameric $\mathrm{Na}\left[\mathrm{Ge}_{4} \mathrm{O}_{16} \mathrm{Al}_{48}(\mathrm{OH})_{108}\left(\mathrm{H}_{2} \mathrm{O}\right)_{24}\right]^{20+}\left(\mathrm{NaGe}_{4} \mathrm{Al}_{48}{ }^{21+}\right)$ resulting from self-condensation of $\varepsilon$ - $\mathrm{GeAl}_{12}{ }^{8+}$ upon thermal aging. 